Pacific Journal of Mathematic 


\title{
ON BROWNIAN MOTION IN A HOMOGENEOUS RIEMANNIAN SPACE
}

\author{
Kôsaku Yosida
}

1. Introduction. Let $R$ be an $n$-dimensional, orientable, infinitely differentiable Riemannian space such that the group $G$ of isometric transformations $S^{*}$ of $R$ onto $R$ constitutes a Lie group transitive on $R$. Consider a temporally homogeneous Narkoff process in $R$, and let $P(t, x, E)$ be the transition probability that the point $x \in R$ is, by this process, transferred into a Borel set $E \subseteq R$ after the lapse of $t$ units of time, $t>0$. We assume that $P(t, x, E)$ is, for fixed $(t, x)$, countably additive for Borel sets $E$ and, for fixed $(t, E)$, Borel measurable in $x$. Then we must have the probability condition

$$
P(t, x, E) \geq 0, P(t, x, R)=1,
$$

and Smoluchowski's equation

$$
P(t+s, x, E)=\int_{R} P(t, x, d y) P(s, y, E) \quad(t, s>0) .
$$

We further as sume that the process is spatially homogeneous:

$$
P(t, x, E)=P\left(t, S^{*} x, S^{*} E\right) \quad \text { for every } S^{*} \in G .
$$

The purpose of the present note is to prove the following:

THEOREM 1. Let $x_{0}$ be any point of $R$ and assume that the Lie subgroup $\left\{S^{*} \in G ; S^{*} x_{0}=x_{0}\right\}$ of $G$ is compact ${ }^{1}$. Let us denote by $d(x, y)$ the distance of two points $x, y \in R$. Then the continuity condition:

$$
\lim _{t \rightarrow 0^{+}} \frac{1}{t} \int_{d(x, y)>\epsilon} P(t, x, d y)=0 \quad \text { for any } \quad \epsilon>0,
$$

implies the condition of Lindeberg's type:

${ }^{1}$ At first, this condition was overlooked. Mr. Seizô Itô kindly remarked that this condition is necessary for the convergence of the integral (2.11) below.

Received August 30, 1951.

Pacific J. Math. 2 (1952), 263-270 


$$
\varlimsup_{t \rightarrow 0+} \frac{1}{t} \int_{R} \frac{d(x, y)^{2}}{1+d(x, y)^{2}} P(t, x, d y)<\infty .
$$

From this theorem we may deduce:

THEовем 2. The finite limits $\left(x=\left(x^{1}, x^{2}, \ldots, x^{n}\right)\right)$

$$
\begin{gathered}
a^{i}(x)=\lim _{t \rightarrow 0^{+}} \frac{1}{t} \quad \int_{d(x, y) \leq \epsilon}\left(y^{i}-x^{i}\right) P(t, x, d y), \\
b^{i j}(x)=\lim _{t \rightarrow 0^{+}} \frac{1}{t} \int_{d(x, y) \leq \epsilon}\left(y^{i}-x^{i}\right)\left(y^{j}-x^{j}\right) P(t, x, d y)
\end{gathered}
$$

exist, independently of the sufficiently small $\epsilon>0$. Moreover, if a real-valued function $f_{0}(x)$ be such that $f_{0}(x), \partial f_{0} / \partial x^{i}, \partial^{2} f_{0} / \partial x^{i} \partial x^{j}$ are bounded and uniformly continuous on $R$, then

$$
\lim _{t \rightarrow 0+} \frac{1}{t}\left(\int_{R} f_{0}(y) P(t, x, d y)-f_{0}(x)\right)=a^{i}(x) \frac{\partial f_{0}}{\partial x^{i}}+b^{i j}(x) \frac{\partial^{2} f_{0}}{\partial x^{i} \partial x^{j}} .
$$

REMARK. In the literature $[4 ; 2 ; 6],(1.8)$ is derived by assuming the condition of Lindeberg's type:

$$
\lim _{t \rightarrow 0+}\left(\int_{R} d(x, y)^{3} P(t, x, d y) / \int_{R} d(x, y)^{2} P(t, x, d y)\right)=0
$$

and some differentiability hypothesis concerning $P(t, x, E)$. Considering the Brownian motion on the real line, Seizô Itô raised the question whether, under the condition of the spatial homogeneity (1.3), "the (almost sure) continuity of the sample motions of the temporally homogeneous Markoff process" which is equivalent to the continuity condition (1.4), would be sufficient to derive Theorem 2. And he proved The orem 2 in the special case where $R=G$ and $G$ is a maximally almost periodic Lie group. The present note gives an extension of his result to general homogeneous space, without the hypothesis of the maximal almost periodicity of the group $G$ of motions of the space $R$. Thus we may define the Brownian motions in a homogeneous Riemannian space $R$ as temporally and spatially homogeneous Markoff processes satisfying the condition (1.4) of continuity.

2. Preliminaries. Let us denote by $C(R)$ the totality of real-valued bounded functions $f(x)$ on $R$ which are uniformly continuous on $R$. The space $C(R)$ is a Banach space by the norm 


$$
\|f\|=\sup _{x}|f(x)|
$$

We define, for any $f \in C(R)$,

$$
\left(T_{t} f\right)(x)=\int_{R} P(t, x, d y) f(y)
$$

then we have, by (1.1),

$$
\sup _{x}\left|\left(T_{t} f\right)(x)\right| \leq \sup _{x}|f(x)|
$$

We have, by (1.3),

$$
\begin{aligned}
&\left(T_{t} f\right)\left(S^{*} x\right)=\int_{R} P\left(t, S^{*} x, d y\right) f(y)=\int_{R} P\left[t, S^{*} x, d\left(S^{*} y\right)\right] f\left(S^{*} y\right) \\
&=\int_{R} P(t, x, d y) f\left(S^{*} y\right),
\end{aligned}
$$

and hence the commutativity

$$
T_{t} S=S T_{t}
$$

where $S$ is defined by

$$
(S f)(x)=f\left(S^{*} x\right),
$$

Thus, if $S^{*} \in G$ be such that $S^{*} x=x^{\prime}$, we have

$$
\left(T_{t} f\right)(x)-\left(T_{t} f\right)\left(x^{\prime}\right)=\left(T_{t} f\right)(x)-\left(S T_{t} f\right)(x)=T_{t}(f-S f)(x) .
$$

By the uniform continuity of $f(x)$, and by (2.3) and (2.6), we see that $\left(T_{t} f\right)(x)$ is bounded and uniformly continuous in $x$. Hence $T_{t}$ defines a bounded linear transformation on $C(R)$ into $C(R)$ such that

$$
\left\|T_{t}\right\|=\sup _{\|f\|=1}\left\|T_{t} f\right\|=1 .
$$

We have, from (1.2),

$$
T_{t+s}=T_{t} T_{s} \quad(t, s>0) .
$$

We have also, from (1.1),

$$
\begin{aligned}
& \left(T_{t} f\right)(x)-f(x)=\int_{R} P(t, x, d y)[f(y)-f(x)] \\
& \quad=\int_{d(x, y) \leq \epsilon} P(t, x, d y)[f(y)-f(x)]+\int_{d(x, y) \geq \epsilon} P(t, x, d y)[f(y)-f(x)] .
\end{aligned}
$$


Thus, in view of conditions (1.4) and (1.1), and the uniform continuity of $f(x)$, we have

$$
\lim _{t \rightarrow 0+}\left(T_{t} f\right)(x)=f(x) \quad \text { boundedly in } x .
$$

Hence $T_{t}$ is weakly continuous in $t$, and therefore, by (2.8) and N. Dunford's theorem [1], $T_{t}$ is strongly continuous in $t$ and

$$
\text { strong } \lim _{t \rightarrow 0^{+}} T_{t} f=f ; \text { that is, } \lim _{t \rightarrow 0+}\left\|T_{t} f-f\right\|=0 .
$$

Therefore we may apply the theory $[3 ; 5]$ of one-parameter semigroups of bounded linear operators to the semigroup $\left\{T_{t}\right\}$. In particular, we have the result:

(2.10) strong $\lim _{t \rightarrow 0+}\left(T_{t} f-f\right) / t=A f$ exists, for those $f$ which constitute a linear subset $D(A)$ of $C(R)$ which is dense in $C(R)$. Moreover, $A$ is a closed linear operator defined on $D(A) \subseteq C(R)$ with values in $C(R)$.

Lemma. Let $g(x) \in C(R)$ vanish outside a compact set. Then the convolution

$$
(f \otimes g)(x)=\int_{G} f\left(S_{y}^{*} x\right) g\left(S_{y}^{*} x_{0}\right) d y
$$

belongs to $D(A)$ if $f$ belongs to $D(A)$. Here $S_{y}^{*}$ is a general element of $G$, dy is a right invariant Haar measure of $G$, and $x_{0}$ is any fixed point of $R$.

Proof. The integral may be approximated by the Riemann sum

$$
\sum_{i=1}^{m} f\left(S_{y_{i}}^{*} x\right) c_{i}
$$

uniformly in $x$. This we see by the uniform continuity of $f(x)$ and the fact that $g(x)$ vanishes outside a compact set. We know, from (2.4), that $A$ is commutative with every $S_{y}$ :

$$
f \in D(A) \text { implies } S_{y} f \in D(A) \text { and } S_{y} A f=A S_{y} f \text {. }
$$

Hence (2.12) belongs to $D(A)$, and we have

$$
A\left(\sum_{i=1}^{m} f\left(S_{y_{i}}^{*} x\right) c_{i}\right)=A\left(\sum_{i=1}^{m}\left(S_{y_{i}} f\right)(x) c_{i}\right)=\sum_{i=1}^{m}\left(S_{y_{i}} h\right)(x) c_{i},
$$

where $h=A f$. Therefore, since $h \in C(R)$, we see that (2.14) converges, when 
$m \rightarrow \infty$, to a function $\in C(R)$ uniformly in $x$. Since $A$ is a closed operator, we must have $(f \otimes g)(x) \in D(A)$.

COROLlary 1. The convolution $(f \otimes g)(x)$ is infinitely differentiable if $g(x)$ is infinitely differentiable.

Proof. It is possible, for sufficiently small $d\left(x, x_{0}\right)$, to choose $S^{*}(x) \in G$ such that

$$
S^{*}(x) x=x_{0} \text { and } S^{*}(x) x_{0} \text { depends analytically on } x^{1}, \ldots, x^{n} .
$$

This we see from the fact that the set $\left\{S_{y}^{*} \in G ; S_{y}^{*} x=x_{0}\right\}$ forms an analytic submanifold of $G$; it is one of the cosets of $G$ with respect to the Lie subgroup $\left\{S_{y}^{*} \in G ; S_{y}^{*} x_{0}=x_{0}\right\}$. Hence, by the right invariance of $d y$, we have

$$
\begin{aligned}
(f \otimes g)(x)=\int_{G} f\left(S_{y}^{*} S^{*}(x) x\right) & \left(g\left(S_{y}^{*} S^{*}(x) x_{0}\right) d y\right. \\
& =\int_{G} f\left(S_{y}^{*} x_{0}\right) g\left(S_{y}^{*} S^{*}(x) x_{0}\right) d y .
\end{aligned}
$$

The right side is infinitely differentiable in the vicinity of $x_{0}$, and

$$
\begin{aligned}
& \frac{\partial^{q_{1}+\cdots+q_{n}}(f \otimes g)(x)}{\partial\left(x^{1}\right)^{q_{1}} \cdots \partial\left(x^{n}\right)^{q_{n}}} \\
& \quad=\int_{G} f\left(S_{y}^{*} x_{0}\right) \frac{\partial^{q_{1}+\cdots+q_{n}} g\left(S_{y}^{*} S^{*}(x) x_{0}\right)}{\partial\left(x^{1}\right)^{q_{1}} \cdots \partial\left(x^{n}\right)^{q_{n}}} d y
\end{aligned}
$$

belongs to $C(R)$.

COROLLARY 2. (i) There exist infinitely differentiable functions $F^{1}(x)$, $F^{2}(x), \ldots, F^{n}(x) \in D(A)$ such that the Jacobian

$$
\frac{\partial\left(F^{1}(x), \cdots, F^{n}(x)\right)}{\partial\left(x^{1}, \cdots, x^{n}\right)} \text { does not vanish at } x=x_{0} \text {. }
$$

(ii) There exists an infinitely differentiable function $F_{0}(x) \in D(A)$ such that

$$
\left(x^{i}-x_{0}^{i}\right)\left(x^{j}-x_{0}^{j}\right) \frac{\partial^{2} F}{\partial x_{0}^{i} \partial x_{0}^{j}} \geq \sum_{i=1}^{n}\left(x^{i}-x_{0}^{i}\right)^{2} .
$$

Proof. In (2.16), $f$ belongs to $D(A)$, which is dense in $C(R)$; and $g(x) \in C(R)$ 
is arbitrary except that $g(x)$ must vanish outside a compact set. Thus, by taking $F(x)=(f \otimes g)(x)$ suitably, we may prove (i) and (ii).

3. Proof of Theorem 1. Because of their functional independence, we may take $F^{1}(x), \cdots, F^{n}(x)$ as local coordinates of the points $x$ which satisfy $d\left(x, x_{0}\right)<\epsilon$ for sufficiently small $\epsilon>0$. Since $F^{i}(x) \in D(A)$,

(3.1) a finite $\operatorname{limit}_{t \rightarrow 0^{+}} \frac{1}{t} \int_{R}\left(F^{i}(x)-F^{i}\left(x_{0}\right)\right) P\left(t, x_{0}, d x\right)$ exists $(i=1, \cdots, n)$.

Because of (1.4), this limit is equal to

$$
\lim _{t \rightarrow 0^{+}} \frac{1}{t} \int_{d\left(x, x_{0}\right) \leq \epsilon}\left(F^{i}(x)-F^{i}\left(x_{0}\right)\right) P(t, x, d x)
$$

independently of the positive constant $\epsilon$. We shall denote these new local coordinates $F^{1}(x), F^{2}(x), \ldots, F^{n}(x)$ by the letters $x^{1}, x^{2}, \cdots, x^{n}$. Then

$(3.1)^{\prime \prime} \quad \lim _{t \rightarrow 0+} \frac{1}{t} \int_{d\left(x, x_{0}\right) \leq \epsilon}\left(x^{i}-x_{0}^{i}\right) P(t, x, d x)=a^{i}\left(x_{0}\right)$ exists

$$
(i=1, \cdots, n),
$$

independently of $\epsilon>0$. The function $F_{0}(x)$ belongs to $D(A)$; hence, by (1.4),

$$
\left(A F_{0}\right)\left(x_{0}\right)=\lim _{t \rightarrow 0+} \frac{1}{t} \underset{d\left(x, x_{0}\right) \leq \epsilon}{ }\left(F_{0}(x)-F_{0}\left(x_{0}\right)\right) P\left(t, x_{0}, d x\right),
$$

independently of $\epsilon>0$. This limit is equal to

$$
\begin{aligned}
& \lim _{t \rightarrow 0+}\left[\frac{1}{t} \underset{d\left(x, x_{0}\right) \leq \epsilon}{ }\left(x^{i}-x_{0}^{i}\right) \frac{\partial F_{0}}{\partial x_{0}^{i}} P\left(t, x_{0}, d x\right)\right. \\
& \left.\quad+\frac{1}{t} \int_{d\left(x, x_{0}\right) \leq \epsilon}\left(x^{i}-x_{0}^{i}\right)\left(x^{j}-x_{0}^{j}\right)\left(\frac{\partial^{2} F_{0}}{\partial x^{i} \partial x^{j}}\right)_{x=x_{0}+\theta\left(x-x_{0}\right)} P\left(t, x_{0}, d x\right),\right] \\
& 0<\theta<1 .
\end{aligned}
$$

The first term in [] has the limit

$$
a^{i}\left(x_{0}\right) \frac{\partial F_{0}}{\partial x_{0}^{i}}
$$


and hence the second term has a limit. Thus, by virtue of (1.1) and (2.19),

$$
\varlimsup_{t \rightarrow 0+} \frac{1}{t} d\left(x, x_{0}\right) \leq \epsilon \sum_{i=1}^{n}\left(x^{i}-x_{0}^{i}\right)^{2} P\left(t, x_{0}, d x\right)<\infty
$$

Hence, by (1.1) and Schwarz's inequality,

(3.4) $\frac{1}{t} \underset{d\left(x, x_{0}\right) \leq \epsilon}{ }\left(x^{i}-x_{0}^{i}\right)\left(x^{j}-x_{0}^{j}\right) P\left(t, x_{0}, d x\right)$ is bounded in $t>0$.

Therefore, by (1.4), we obtain (1.5).

4. Proof of Theorem 2. Since $c_{i j}(\epsilon)$ is of order $\epsilon$, we have

$$
\begin{aligned}
& \frac{\left(T_{t} f_{0}\right)\left(x_{0}\right)-f_{0}\left(x_{0}\right)}{t}=\frac{1}{t} \int_{d\left(x, x_{0}\right) \leq \epsilon}\left(x^{i}-x_{0}^{i}\right) P\left(t, x_{0}, d x\right) \frac{\partial f_{0}}{\partial x_{0}^{i}} \\
& +\frac{1}{t} d\left(x, x_{0}\right) \leq \epsilon \\
& +\frac{1}{t} d\left(x, x_{0}^{i}-x_{0}^{i}\right)\left(x^{j}-x_{0}^{j}\right) P\left(t, x_{0}, d x\right) \frac{\partial^{2} f_{0}}{\partial x_{0}^{i} \partial x_{0}^{j}} \\
& +\frac{1}{t} d\left(x, x_{0}^{i}-x_{0}^{i}\right)\left(x^{j}-x_{0}^{j}\right) c_{i j}(\epsilon) P\left(t, x_{0}, d x\right) \\
& \left(f_{0}(x)-f_{0}\left(x_{0}\right)\right) P\left(t, x_{0}, d x\right) \\
& =I_{1}(t, \epsilon)+I_{2}(t, \epsilon)+I_{3}(t, \epsilon)+I_{4}(t, \epsilon) .
\end{aligned}
$$

Now

$$
\begin{aligned}
& \lim _{t \rightarrow 0^{+}} I_{1}(t, \epsilon)=a^{i}\left(x_{0}\right) \frac{\partial f_{0}}{\partial x_{0}^{i}} \text { by }(3.1)^{\prime \prime} ; \lim _{\epsilon \rightarrow 0+} I_{3}(t, \epsilon)=0 \text { by (3.4); } \\
& \lim _{t \rightarrow 0^{+}} I_{4}(t, \epsilon)=0 \text { by (1.4). }
\end{aligned}
$$

On the other hand, by (1.4) and (3.4), the finite limits

$$
\begin{aligned}
& \varlimsup_{t \rightarrow 0+} \frac{1}{t} \int_{d\left(x, x_{0}\right) \leq \epsilon}\left(x^{i}-x_{0}^{i}\right)\left(x^{j}-x_{0}^{j}\right) P\left(t, x_{0}, d x\right)=b_{1}^{i j}\left(x_{0}\right), \\
& \varliminf_{t \rightarrow 0^{+}} \frac{1}{t} \int_{d\left(x, x_{0}\right) \leq \epsilon}\left(x^{i}-x_{0}^{i}\right)\left(x^{j}-x_{0}^{j}\right) P\left(t, x_{0}, d x\right)=b_{2}^{i j}\left(x_{0}\right)
\end{aligned}
$$


exist and are independent of $\epsilon>0$. Let us, in place of $f_{0}(x)$, take $F_{0}(x)$ of the form $(f \otimes g)(x)$. We may choose $F_{0}(x)$ such that $\partial F_{0} / \partial x_{0}^{i} \partial x_{0}^{j}$ assumes values arbitrarily near to given constants $\alpha_{i j}(i, j=1, \cdots, n)$. Thus, by (4.1) and (4.2) and the fact $F_{0}(x) \in \nu(A)$, we see that $b_{1}^{i j}\left(x_{0}\right)$ must be equal to $b_{2}^{i j}\left(x_{0}\right)$. Ilence $(1.7)$ is proved.

Therefore, by (1.4), (3.1)", and (4.2), we obtain (1.8).

\section{REFERENCES}

1. Nelson Dunford, On one-parameter groups of lınear transformations, Ann. of Math. 39 (1938), 569-573.

2. W. Feller, Zur Theorie der stochastischen Prozesse, Math. Ann. 113 (1936), $113-160$.

3. E. Hille, Functional analysis and semi-groups, American Mathematical Society, New York, 1948.

4. A. Kolmogoroff, Zur Theorie der stetigen zufälligen Prozesse, Math. Ann. 108 (1933), 149-160.

5. K. Yosida, On the differentiability and the representation of one-parameter semigroups of linear operators, J. Math. Soc. Japan 1 (1948), 15-21.

6. - An extension of Fokker-Planck's equation, Proc. Japan Acad. 25 (1949), No. 9, 1-3.

Mathematical INSTITUTE, NagOYA UNIVERSITY. 


\section{PACIFIC JOURNAL OF MATHEMATICS}

\section{EDITORS}

R. M. RoBINSON

University of California Berkeley 4, California

\section{*R. P. Dilworth}

Califomia Institute of Technology Pasadena 4, California

\section{E. F. BECKENBACH, Managing Editor}

University of California

Los Angeles 24, California

*During the absence of Herbert Busemann in 1952.

\section{ASSOCIATE EDITORS}

\author{
R. P. DILWORTH \\ HERBERT FEDERER \\ MARSHALL HALL
}

\author{
P. R. HALMOS \\ HEINZ HOPF
}

R. D. JAMES

\author{
BØRGE JESSEN \\ PAUL LÉVY \\ GEORGE PÓLYA
}

\author{
J. J. STOKER \\ E. G. STRAUS
}

KÖSAKU YOSIDA

\section{SPONSORS}

UNIVERSITY OF BRITISH COLUMBIA

CALIFORNIA INSTITUTE OF TECHNOLOGY

UNIVERSITY OF CALIFORNIA, BERKELEY

UNIVERSITY OF CALIFORNIA, DAVIS

UNIVERSITY OF CALIFORNIA, LOS ANGELES

UNIVERSITY OF CALIFORNIA, SANTA BARBARA

OREGON STATE COLLEGE

UNIVERSITY OF OREGON

\author{
UNIVERSITY OF SOUTHERN CALIFORNIA \\ STANFORD UNIVERSITY \\ WASHINGTON STATE COLLEGE \\ UNIVERSITY OF WASHINGTON \\ AMERICAN MATHEMATICAL SOCIETY \\ NATIONAL BUREAU OF STANDARDS, \\ INSTITUTE FOR NUMERICAL ANALYSIS
}

Mathematical papers intended for publication in the Pacific Journal of Miathematics should be typewritten (double spaced), and the author should keep a complete copy. Manuscripts may be sent to any of the editors. All other communications to the editors should be addressed to the managing editor, E. F. Beckenbach, at the address given above.

Authors are entitled to receive 100 free reprints of their published papers and may obtain additional copies at cost.

The Pacific Journal of Mathematics is published quarterly, in March, June, September, and December, by the University of California, Berkeley 4, California. The price per volume (4 numbers) is $\$ 8.00$; single issues, $\$ 2.50$. Special price to individual faculty members of supporting institutions and to individual members of the American Mathematical Society: $\$ 4.00$ per volume; single issues, $\$ 1.25$.

Subscriptions, orders for back numbers, and changes of address should be sent to the publishers, University of California Press, Berkeley 4, California.

Printed at Ann Arbor, Michigan. Entered as second class matter at the Post Office, Berkeley, California.

\section{UNIVERSITY OF CALIFORNIA PRESS • BERKELEY AND LOS ANGELES}




\section{Pacific Journal of Mathematics}

\section{Vol. 2, No. $2 \quad$ February, 1952}

L. Carlitz, Some theorems on Bernoulli numbers of higher order...

Watson Bryan Fulks, On the boundary values of solutions of the heat equation........................................ 141

John W. Green, On the level surfaces of potentials of masses with fixed center of gravity................................... 147

Isidore Heller, Contributions to the theory of divergent series .......... 153

Melvin Henriksen, On the ideal structure of the ring of entire functions . . . 179

James Richard Jackson, Some theorems concerning absolute neighborhood retracts........................................ 185

Everett H. Larguier, Homology bases with applications to local connectedness ................................... 191

Janet McDonald, Davis's canonical pencils of lines ................ 209

J. D. Niblett, Some hypergeometric identities . . . . . . . . . . . . . . . . . . 219

Elmer Edwin Osborne, On matrices having the same characteristic equation...................................... 227

Robert Steinberg and Raymond Moos Redheffer, Analytic proof of the

Lindemann theorem ................................. 231

Edward Silverman, Set functions associated with Lebesgue area ......... 243

James G. Wendel, Left centralizers and isomorphisms of group algebras . . 251

Kosaku Yosida, On Brownian motion in a homogeneous Riemannian space. 